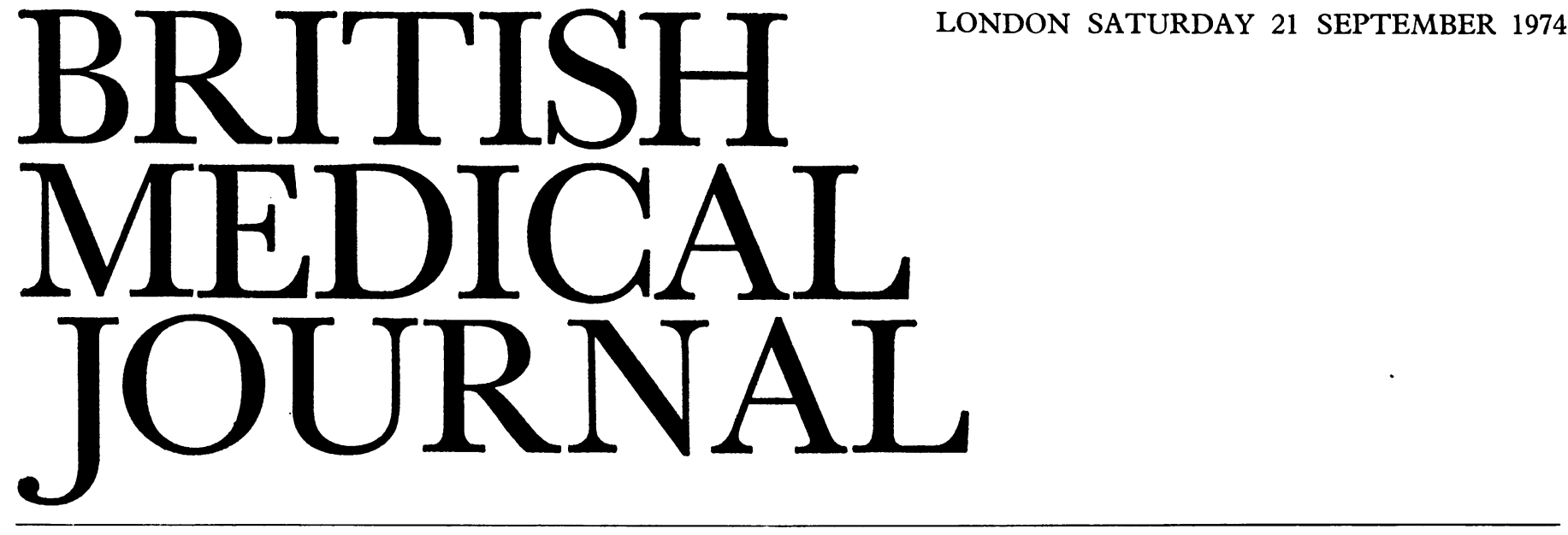

\title{
A Human Right
}

Up to early historical times the approximate growth rate of the human population was $2 \%$ per 1,000 years. It is now $2 \%$ per year. ${ }^{1}$ This 1,000 -fold increase in the rate of growth is at last recognized almost everywhere as one of the main menaces that man faces today. But has the medical profession, so largely responsible for creating the danger, any part to play in averting it? This question is less straightforward than it seems, for the recent Population Conference at Bucharest showed that some people regard the real problem as being one of distributing the world's resources more equally.

In the first week of September an International Conference on the Physician and Population Change was held in Stockholm. It had been organized by the World Medical Association in collaboration with the World Federation of Medical Education, the International Planned Parenthood Federation, and the World Health Organization. Some critics on the sidelines had suggested that a conference on this theme coming so soon after the one at Bucharest could have little new to say, but the planners' decision was quickly justified. Several speakers at the W.M.A. conference had also been at Bucharest and were severely critical of the way things had gone there. To doctors it was evident that the present rate of population growth is far too high for people's health, that it is the increasing desire of people everywhere to have the means of limiting their fertility, and that doctors have a duty to help them to do so. Several speakers indeed spoke of fertility control as a basic human right which doctors must do all they can to help their patients achieve. Nor did anyone disagree with the view expressed in the opening address by Dr. J. F. Patinô (absent owing to illness) that mankind is already suffering from the ills of overpopulation. This was the accepted keynote of the conference.

What then is the role of medical men and women in diagnosis, advice, treatment? Here there are two divergent schools of thought. Dr. R. J. Ravenholt, director of the Office of Population of the U.S. Agency of International Development, represented one side of the argument, namely, that if the full range of contraceptive measures, physical, chemical, and operative, are made available a rapid and profound decrease in fertility will follow. The opposite view came from Dr. L. Engstrom, chief medical officer of the Division of Family Health in the W.H.O., who said that crash programmes offering only family planning had not been successful. The prime need was to get the social structure right through education, especially in many of the poor agrarian parts of the world. Both sides have facts and figures to support their theses, which are each true in selected areas of the world. But the general lesson to come out of this debate was that programmes of fertility control must be adopted specifically to the needs of each community. There is no single panacea such as vasectomy, pills, abortion, or condoms that would reduce population growth. One speaker did observe, however, that there is a world shortage of condoms, which is becoming serious, and another that no developed country had brought down its birth rate without recourse to abortion, legal or illegal.

Many speakers were critical of the poor response doctors had made so far in most countries to their patients' demands for fertility control. The birth control movement grew up largely outside the medical profession and often against the opposition of leading doctors as well as apathy from the rest. Today it would be hard to find a medical school preparing its students thoroughly enough to cope with the family planning problems that will loom so large in most of their patients' lives. Nor is it simply a question of imparting knowledge to students. Clinical teachers if they know their job take great pains to show their students how to approach patients worried about the future or worn out by their pain. Yet very little is taught on patients' anxieties about birth control. As Dr. J. D. Wray, of the Rockefeller Foundation at Bangkok, emphasized, knowledge without the right attitude is worthless, and he had found the right attitude to be lacking surprisingly often. The lesson of his experience as of several other speakers' was that if healthy and humane control of fertility is to be achieved, it is now the medical profession who must change more than their patients or communities. To this end Dr. T. Luukkainen, of Helsinki University, wanted the W.M.A. to ask the United Nations to stimulate its member States to found institutes for the teaching of medical personnel in family planning and research.

An approach with a slightly different emphasis is to train lay staff to carry out most of the family planning work either under medical supervision or as members of a health team of which a doctor would not necessarily have charge. A few speakers advocated selling the Pill over the counter in shops and markets, regarding its hazards as so greatly outweighed by its benefits as not to require medical control. Dr. Malcolm Potts, of the International Planned Parenthood Federation, London, developed the theme of taking family planning to the people. According to him men in Ireland can get a vasectomy more 
easily than a condom, whereas in Stockholm a vasectomy is practically impossible while condoms are readily bought. (In fact, as members of the conference may have noticed, they were on sale in slot machines in the streets.) Like many other speakers he spoke of induced abortion as a part of family planning, but probably the precise part it takes in the scheme of things remains a subject of irreconcilable differences. A speaker from France declared outright that his country is against abortion as a form of birth control. Another from West Germany reminded the meeting of the W.M.A.'s Oslo Declaration. ${ }^{2}$ This states as one of its principles that "Abortion should be performed only as a therapeutic measure." The utterances of some of the speakers hardly seemed to be bounded by that clause, but there was no attempt to get it altered. Much depends on what is meant by the term "therapeutic measure," and a unanimous opinion on its definition would be most unlikely at present.

The contributions that physicians from Ghana made at this conference both in the chair and at the rostrum were particularly notable for their good sense and broad humanity. And Dr. Ofosu-Amaah, senior lecturer in child health at Ghana medical school, caught his audience's attention with a striking phrase- "Physicians are the advocates of the world's poor." Will they be so, he wondered, in the regulation of fertility ? In some parts of the world all that is needed now is for contraceptive methods to be readily available for the people who want them. In other parts they must be available to all who need them and can be educated to want them. Elsewhere again considerable social change is needed so that a man is not compelled to produce a lot of children, especially sons, to keep him in old age owing to lack of any other means of support. But the oft-repeated view that fertility control is a basic human right did not find any dissentients at the conference. Much help will be sought from the medical profession in the immediate future, and the conference laid down some guidelines in "A Strategy for Action." Doctors in general are still too lethargic in meeting the clamant need of their patients to control reproduction rationally.

\footnotetext{
1 Bevelson, B., et al., Reports on Population/Family Planning, No. 15, January 1974.

2 British Medical fournal, 1970, 3, 581.

3 After slight revision to be published in the World Medical fournal and
} with the full proceedings, in book form.

\section{Burden of Schizophrenia}

Vocal protests are made about the prestige branches of the N.H.S., such as medicine and surgery, but the voice of a minor subsidiary such as mental health can scarcely be heard above the din since those with whom it deals (or purports to deal) are the most helpless, inarticulate, and politically impotent section of the community. The extent of consumer dissatisfaction cannot be measured by asking the hapless sufferers from crippling mental disorders themselves; it can, however, be learnt by questioning those who have had to take over these patients' care once the apparently unpopular and much maligned mental hospitals have shuffled off their responsibility.

Questions are now at last being asked in plenty: and the answers received are gravely disconcerting. Some very pertinent inquiries were made ${ }^{1}$ by the Psychiatric Rehabilitation Association into the fate of sufferers from schizophrenia, the most common and yet the most devastating of all forms of mental illness, once they had been discharged from a mental hospital into a sector of East London. It was found that of 174 schizophrenics discharged to known addresses only 94 could be traced within a year. Of those with whom contact had been maintained 29 were unsatisfactorily housed, 33 were without employment, and 28 showed evidence of grave self-neglect. Of those who had vanished it can be assumed-as it could of a similar proportion of those discharged into other predominantly urban areasthat an unwholesome number have been redistributed in a variety of socially undesirable ways: to doss-houses, park benches, and prisons. Some, perhaps the most fortunate, have been readmitted to mental hospitals informally or under compulsory orders.

But for those schizophrenics who still have roots in their communities it is the relatives, predominantly the parents, who are responsible for their primary care and on whom the burden of that care falls. Another voluntary organisation, the National Schizophrenia Fellowship, a middle-class organization, has of late emerged and taken upon itself the task of asking questions and so letting some of the deficiencies of community care be known. Earlier this year it published, ${ }^{2} 3$ "Living with Schizophrenia," for the most part anecdotal in content, and though poignant and distressing in its revelations it lacks scientific objectivity and methodology. The second publication, however, is a report ${ }^{4}$ of an excellent research project undertaken by Mrs. Clare Creer and Professor John Wing, in which the scientific shortcomings of the first are made good.

The report describes the problems of 50 relatives of people with schizophrenia living in three separate areas of England and compares them with 30 relatives of a representative group of schizophrenics living in Camberwell, London-a mainly working class area but one reasonably well provided with community care facilities. It is the similarities not the differences between the groups that are important. The one message that shines out like a beacon is that if today's psychiatrists, or antipsychiatrists for that matter, have forgotten (if indeed some of them ever knew) what a crippling, disturbing, unpredictable disease chronic schizophrenia can be, then they could with profit exchange places for a time with the relatives.

The nature of the cross they have to bear is well-illustrated by quotations given in the report. The "discordance of living constantly with abnormality" is a heart-rending phrase used by one relative that sticks in the memory like a burr. Two parents ask wistfully for nothing more than to have "one week alone together" or "an evening off." Yet another relative said: "You can put him in a back ward for the rest of his days and then you have written him off, his life is finished. Or you can have him at home, and then you have to accept that you will have to alter your whole life. You will never be free again." The report concludes: "This relative painted a black picture but in many cases it appears to be an accurate. one, since alternatives to hospital, such as supervised hostels, are so few in number, and help for the family who choose to care for a patient at home is so unreliable and inadequate."

One question which pinpoints the consumer rights in this scandalously neglected branch of the N.H.S. and the Social Services in general was posed by $\mathrm{Mr}$. John Pringle, honorary director of the National Schizophrenia Association, in its first publication. ${ }^{2} \mathrm{He}$ asked simply: "Cannot a humane society do better than this for one of the most vulnerable and least befriended sections of its people?" He referred to the patients: but he might equally have referred to those 